\title{
Высокоинформативные методы системного анализа безопасности и качества пищевой продукции
}

\author{
А. Н. Алёшин, к. Ф.- М. н. \\ nanoindustry@technosphera.ru
}

\begin{abstract}
Компания "МС-АНАЛИТИКА" 25 апреля 2019 года на базе Московского государственного университета пищевых производств провела семинар «Высокоинформативные методы системного анализа безопасности и качества пищевой продукции". В семинаре приняли участие специалисты фирмы-изготовителя оборудования Thermo Fisher Scientific, представители Всероссийского масс-спектрометрического общества, а также специалисты МГУПП, лаборатории контроля качества сети "Азбука вкуса", компании "Вимм-Биль-Данн" и другие организации, использующие в своей работе оборудование компании.
\end{abstract}

Программа семинара включала вопросы разработки методов (и методик) анализа контроля пищевой продукции и продовольственного сырья, материалы по анализу содержания пестицидов, диоксинов, остаточных ветеринарных препаратов в продуктах питания (антибиотиков) и прочих вредных веществ.

Тон семинару задало выступление О. В. Мироненко из Национального союза производителей и потребителей органической продукции "Система сертификации

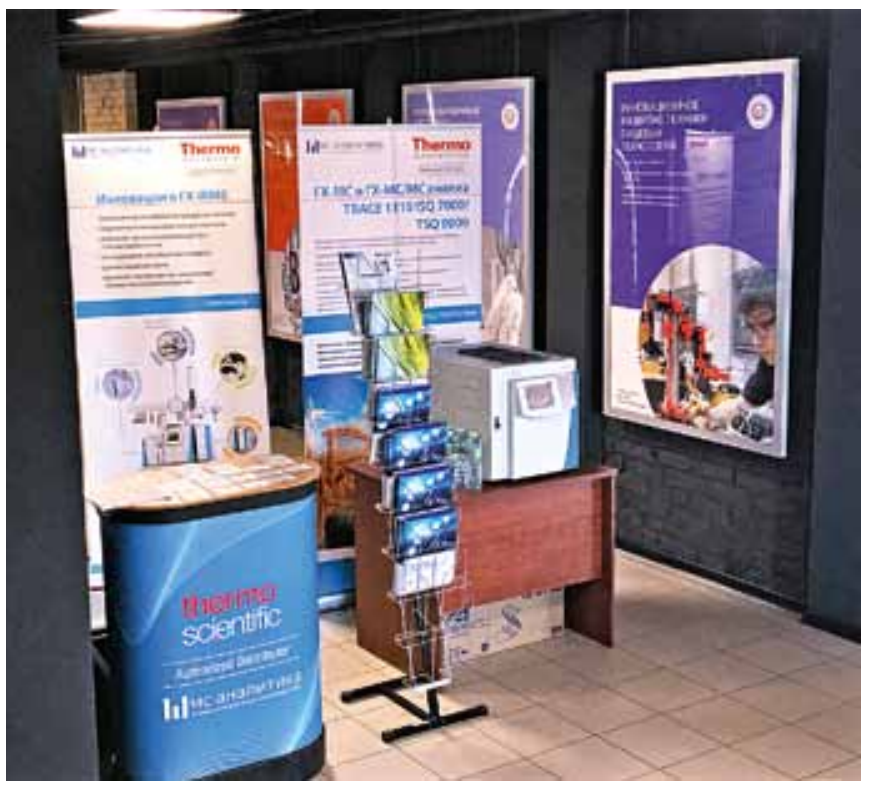

Puc. 1. Совместный семинар "МС-АНАЛИТИКА» и Thermo Fisher Scientific органической продукции", в котором докладчик охарактеризовал рынок органической продукции в мире, а также состояние и перспективы российского рынка, обосновав его направленность на внутреннего потребителя. Согласно приведенным данным, объем производства органических продуктов в России сегодня составляет 0,02\% от мирового (в 2016 году это составляло сумму 25-30 млн евро), а в перспективе - должен достигнуть 10-15\% от мирового объема в 2025 году (достигнув величины 20-30 млрд евро), при стоимости органического рынка России в 160 млн евро с перспективой роста до 5-10 млрд евро к 2015 году. Экспорт органической продукции с менее чем 1 млн евро сейчас должен возрасти до 5-10 млрд евро к этому же сроку. Важной задачей является также и увеличение потребления органической продукции в России. В этом году только около 1\% населения России потребляет органическую продукцию, но к 2025 году долю таких потребителей планируется довести до 20\%. Для этого есть все возможности, ведь Россия обладает 0,5\% сертифицированных земель от мирового объема (что соответствует площади 289,89 тыс га) и легко может достичь 30\% (более 13 млн га земли), что сделает нашу страну лидером в задействованных сельскохозяйственных площадях под органическую продукцию. Главное препятствие на пути к выполнению этих задач - беспрецедентно низкое число сертифицированных компаний (0,005\% от общего количества в мире), в абсолютных цифрах - около 100. Расчеты показывают, что необходимо сертифицировать более 2\% от мирового числа компаний, что составит 20 тысяч сертифицированных компаний России к 2015 году. Во исполнение решений Послания Президента Федеральному Собранию от 20 февраля 2019 года утвержден 


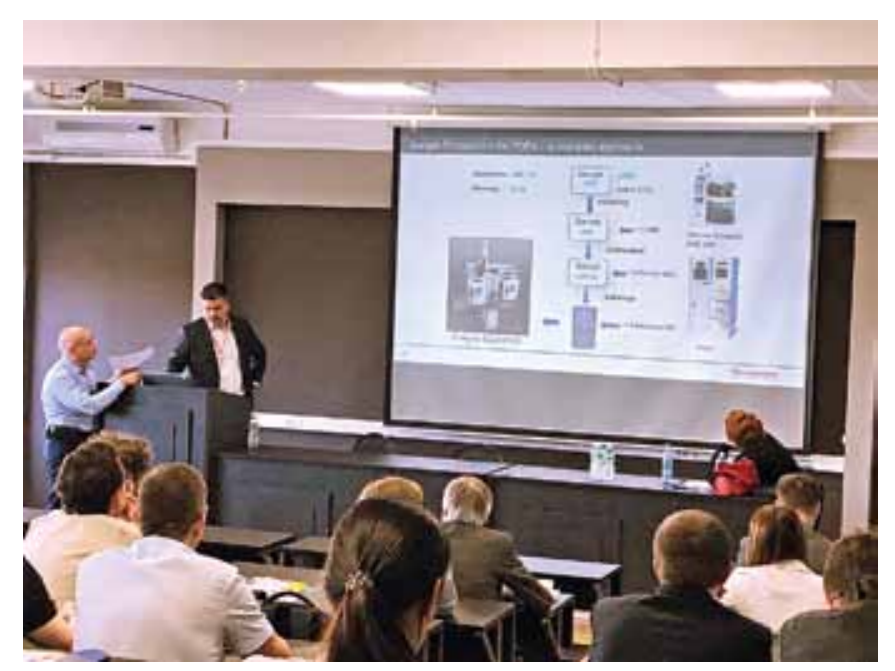

Puc. 2. Мuхал Годула докладывает об обнаружении и выявлении диокСИнов

план мероприятий ("дорожная карта») «...по созданию российских защищенных брендов экологически чистой сельскохозяйственной продукции, сырья и продовольствия в целях их продвижения на внутренний и внешние рынки, предусматривающий в том числе и формирование системы контроля за соблюдением требований к производству и обороту указанных товаров", опираясь на подписанный Президентом РФ от 03 августа 2018 года закон "Об органической продукции". В РФ утверждены три национальных стандарта: ГОСТ Р 56104-2014 «Продукты пищевые органические. Термины и определения", ГОСТ Р 57022-2016 "Продукция органического производства. Порядок проведения добровольной сертификации органического производства", а с 1 января 2018 года вступил в силу межгосударственный стандарт ГОСТ 33980-2016 «Продукция органического производства, правила производства, переработки, маркировки и реализации (CAC / GL 32-1999, NEQ)», началась процедура согласования стандарта с IFOAM International.

Развитие индустрии органической продукции требует эффективных методов контроля качества. Об одних из современных семейств методов в своем докладе рассказал П.В.Кудан, представлявший группу компаний "МС-АНАЛИТИКА": "Суть методов ГХ-МС (газовая хроматография и масс-спектрометрия) и ВЭЖХ-МС (высокоэффективная жидкостная хроматография и масс-спектрометрия) и причины их использования при анализе пищевой продукции". Аналитическое оборудование для реализации этих методов производит компания Thermo Fisher Scientific, разработавшая более 40 лет назад тройной квадрупольный масс-анализатор и орбитальную электростатическую ловушку высокого разрешения (Orbitrap).

В частности, основным методом определения диоксинов является хромато-масс-спектрометрия высокого разрешения. Этому методу была посвящена презентация доклада
Е. С. Бродского "Определение полихлорированных дибензоп-диоксинов в пищевой продукции" из лаборатории аналитической экотоксикологии Института проблем экологии и эволюции им. А. Н. Северцова (ИПЭЭ РАН). Практически во всех выступлениях на семинаре докладчики касались проблемы загрязнения окружающей среды диоксинами и предлагали методы их выявления и защиты от них населения и окружающей среды.

Диоксины представляют собой шестичленные гетероциклы, в которых два атома кислорода связаны с двумя этиленовыми мостиками. Под этим обобщенным названием подразумевают большие группы полихлордибензопарадиоксинов (ПХДЦ), полихлордибензодифуранов (ПХДД) и полихлордибифенилов (ПХДФ). Всего насчитывают более четырех сотен видов диоксинов, но только 17 конгенеров ПХДД (7 веществ) и ПХДФ (10 веществ), имеющих замещение галоидом в положениях 2, 3, 7, 8, они и являются сильнодействующими ядами. Согласно данным A. Poland, A. Kende, опубликованным в Fed Proceeding в 1976 году, токсичность диоксина составляет $3,1 \cdot 10^{-9}$ моль / кг веса морской свинки (для сравнения, ботулинический токсин обладает токсичностью 3,3 10-17 моль / кг веса мыши). Диоксины представляют собой твердые бесцветные кристаллические вещества, химически инертные и термически стабильные, разлагающиеся при нагревании до температур выше $750^{\circ} \mathrm{C}$.

Опасность диоксинов состоит не только в их канцерогенности, но и в разрушении ими эндокринных гормональных систем, особенно тех, которые связаны с половым созреванием, вредным воздействием на критических стадиях развития эмбриона, например, поражение нервной системы плода, нарушение функционирования иммунной системы (как при ВИЧ-инфицировании), приводящее к возрастанию чувствительности к инфекционным заболеваниям (включая так называемый "химический СПИД"), возникновению онкологических заболеваний, и, что самое опасное, эти

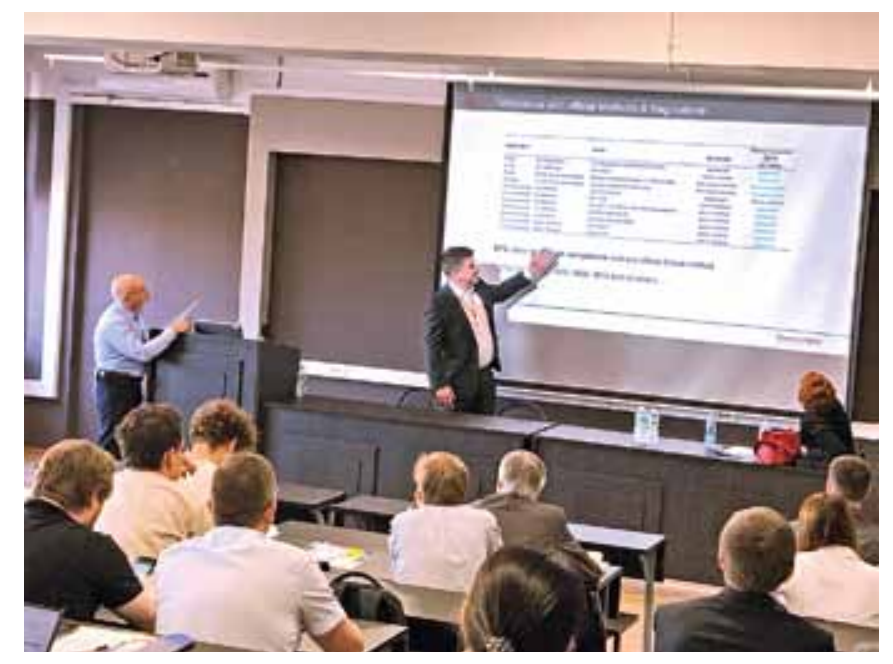

Puc. 3. Доклад о масс-спектрометрии загрязнений пищевых проб 


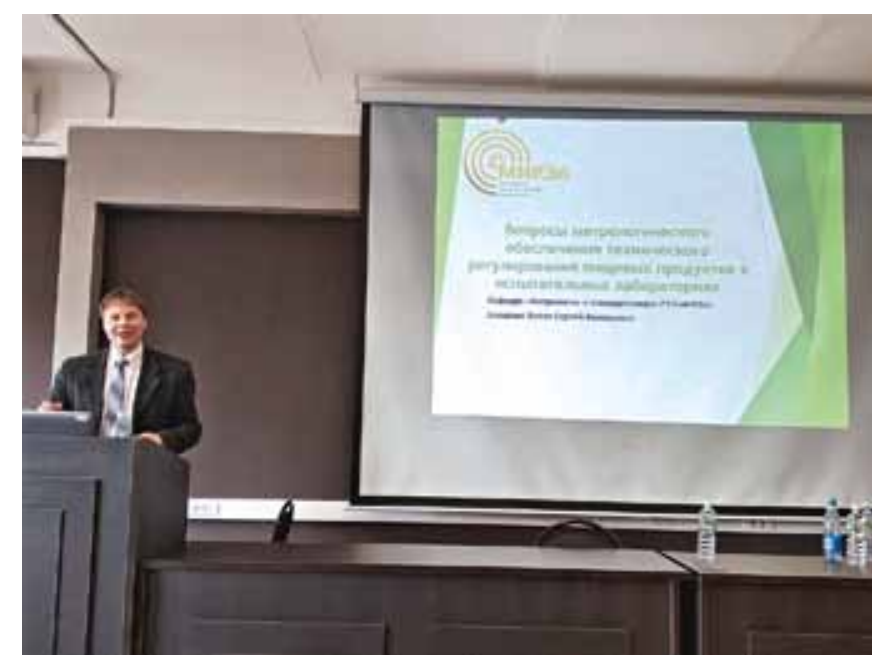

Puc. 4. Доклад С. Белова о метрологии в тестовых пабораториях

дефекты могут передаваться по наследству. Период полураспада диоксинов в организме человека оценивается в 7-11 лет.

Гости семинара из компании Thermo Fisher Scientific представили целый ряд докладов, посвященных подготовке образцов и определению содержания диоксинов в них. Михал Годула (Michal Godula) в докладах «Рутинный анализ диоксинов и других полигалогенированных загрязнителей методами ГХ-МС, метод анализа диоксинов, дибензофуранов и других СОЗ с помощью масс-спектрометрии высокого разрешения (TSQ 9000, DFS)", «Подходы к анализу добавленных веществ при производстве упаковочных материалов и упаковочных загрязнений" и "Целевой скрининг и количественное определение пестицидов в пищевых продуктах с использованием ГХ-МС / MC TSQ 9000" подробно рассказал о процедуре подготовки образцов для массспектрометрии, действующих стандартах и методике измерений, а также поднял важные вопросы о влиянии упаковки и сопутствующих факторов на загрязнение пищевой продукции, что должно быть учтено при проведении идентификации диоксинов и прочих загрязнителей и ядовитых веществ. Ласло Холлоси (Laszlo Hollosi) в своих презентациях "Современные и будущие методы целевого анализа остаточных загрязняющих веществ в пищевых продуктах и окружающей среде, ГХ-МС и ВЭЖX-МС / MC анализ ветеринарных препаратов, микотоксинов и пестицидов в сочетании с системами подготовки образцов Quenchers, ASE, Autotrace» и «Нецелевой скрининг загрязняющих веществ в пищевых продуктах с использованием высокоточной массспектрометрии и передовых инструментов анализа данных - Q Extractive, Quenchers, Compound Discoverer" остановился на особенностях применения оборудования компании Thermo Fisher Scientific для выявления диоксинов и прочих загрязнителей в различных средах, продуктах питания и лекарственных препаратах.

Оригинальные методики выявления загрязнителей и опыт использования оборудования отечественных лабораторий были изложены в докладах М. Ю. Ганина (МгупП) "Применение изотопной масс-спектрометрии" в оценке качества и безопасности пищевой продукции" и С. В. Белова (МИРЭА) «Вопросы метрологического обеспечения технического регулирования пищевых продуктов в испытательных лабораториях".

Обмен опытом между отечественными исследователями и представителями компании - производителя высокотехнологичного оборудования, на семинаре проходил в атмосфере взаимного интереса, а представленные авторами выводы исследований и методики экспериментов живо обсуждались слушателями, переходя в полномасштабные дискуссии, результатом которых стала выработка общего понимания проблем и выявление путей их решения. Плодотворная работа семинара продолжалась до глубокого вечера, выйдя за рамки предусмотренного времени, что подчеркнуло актуальность его тематики и высокий уровень заинтересованности его участников и слушателей.

По окончанию семинара старший менеджер отдела продаж компании Thermo Fisher Scientific Михал Годула любезно ответил на несколько наших вопросов.

\section{Мистер Годула, какие цели вы ставили, какие идеи хотели донести до слушателей семинара?}

Я очень высоко ценю уровень слушателей, их подготовку и желание получить новую информацию о нашем оборудовании, методиках измерений и новинках. Я постарался в своих докладах осветить весть спектр возможностей, открывающихся перед теми, кто воспользуется нашим оборудованием и сможет повлиять на снижение уровня загрязнений окружающей среды. В частности, я расскажу о специально разработанных решениях для определения содержания трудно детектируемых веществ, таких как диоксины, с использованием масс-анализатора TSQ 9000 GC-MS/MS, ловушки Orbitrap GC-MS и массспектрометра DFS GC-HRMS. С другой стороны, из докладов коллег я узнал много новой интересной информации, которую буду использовать в работе для улучшения методик получения результатов, а некоторые идеи передам разработчикам оборудования.

\section{Мистер Годула, как вы оцениваете российский рынок с точки зрения вашей компании?}

Российский рынок - один из крупнейших, он очень важен для нашей компании, мы рассматриваем его как очень интересный и перспективный участок работы. Мы работаем тут уже более 40 лет. Мы представляем на 
российском рынке все наши новинки и уникальные разработки, сотрудничаем с дистрибьюторами. Наша компания носит инновационный характер, и мы постоянно изменяемся, реагируя на рынки сбыта и вызовы времени Нашей целью является улучшение жизни людей, очистка и защита окружающей среды, повышение качества жизни во всех регионах мира. Помимо продаж, мы создали качественное сервисное обслуживание по наивысшим стандартам, принятым в США и Западной Европе, и мы делаем это тут, в России, организовывая обучение, тренинги, склады запасных частей, плотно работаем с нашими дистрибьюторами в России.

Мистер Годула, как работает ваша компания в России в условиях экономических и политических санкций?

Наша компания соблюдает законы, политические рекомендации и старается эффективно работать в условиях санкций с Россией, мы жестко ограничены в сотрудничестве только с такими государствами, как Северная Корея, Ираном, но если санкции мягкие или имеют рекомендательный характер, мы продолжаем работать и налаживать связи, сотрудничество и бизнес с интересными для нас партнерами. Существуют, конечно, некоторые ограничения, но мы стараемся их преодолевать законным образом.
Мистер Годула, чтобы вы хотели сказать читателям нашего журнала?

Наша компания крупнейшая в этом сегменте рынка, мы призываем работать с нами, поскольку наше оборудование одно из лучших, а может быть, и лучшее в мире, мы хорошо понимаем нужды и запросы наших клиентов. Мы хотели бы, чтобы на страницах вашего журнала появлялись материаль о нашей компании и оборудовании, чтобы читатели имели возможность узнавать о наших инновациях и достижениях. Прошедший семинар - это еще один шаг к расширению сотрудничества и взаимовыгодному обмену информацией и идеями, полностью совпадающими с целями нашей компании. Мы всегда готовы осветить особенности и преимущества нашего оборудования и новейших методик исследований. Я хотел бы поблагодарить всех организаторов семинара, предоставивших нам возможность так эффективно поработать сегодня, компанию "МС-АНАЛИТИКА" за идею и проведение такого крупного события на регулярной основе, заботу об удобстве участников, профессиональных переводчиков и руководство Московского государственного университета пищевых производств, а также всех участников, создавших атмосферу подлинно научного поиска и высокого уровня дискуссий по всем проблемам и вопросам, поднимавшимся на сегодняшнем семинаре.

\section{TATАРСТАНСКИЙ} НЕФТЕГАЗОХИМИЧЕСКИЙ
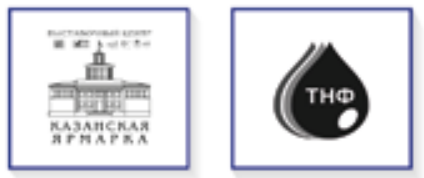

\section{ФОРУM \\ 2-4 сентя6ря 2019, Казань}

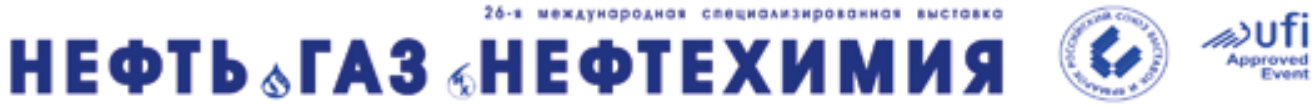

Opганизаторы:

Правительство Республики Татарстан

$0 \mathrm{AO}$ жКазанская ярмарка»

При поддержке:

Президента Республики Татарстан

Россия, 420059, г. Казань

Оренбургский тракт, 8

$\mathrm{OAO}$ жКазанская ярмарка»

тел.(843) 212-21-44

www.oilexpo.ru, www.expokazan.ru

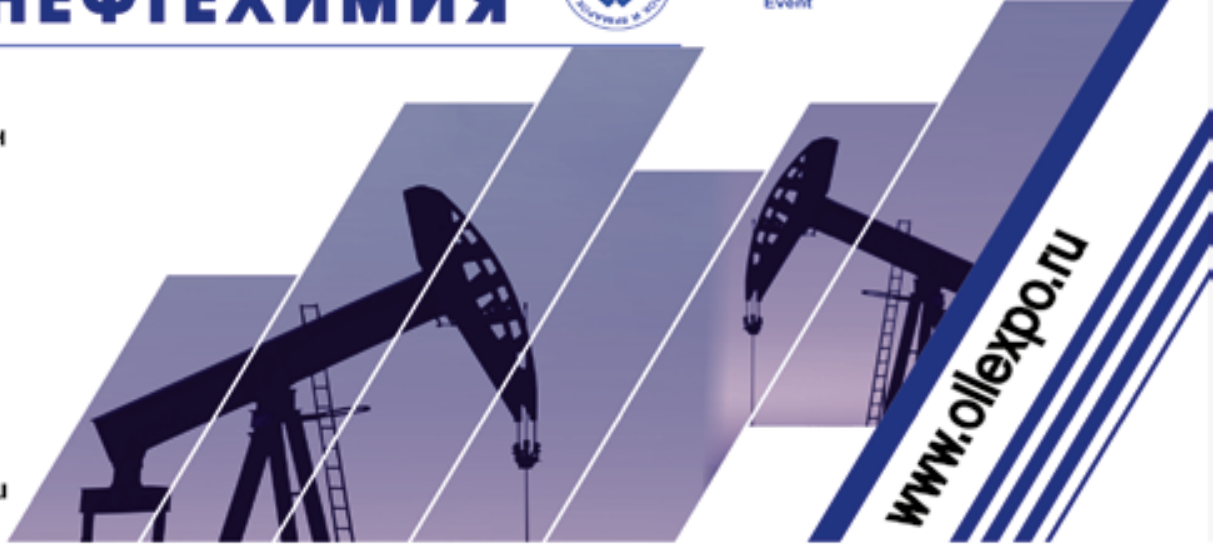

